\title{
Imagination inflation: Imagining a childhood event inflates confidence that it occurred
}

\author{
MARYANNE GARRY, CHARLES G. MANNING, and ELIZABETH F. LOFTUS \\ University of Washington, Seattle, Washington \\ and \\ STEVEN J. SHERMAN \\ Indiana University, Bloomington, Indiana
}

\begin{abstract}
Counterfactual imaginings are known to have far-reaching implications. In the present experiment, we ask if imagining events from one's past can affect memory for childhood events. We draw on the social psychology literature showing that imagining a future event increases the subjective likelihood that the event will occur. The concepts of cognitive availability and the source-monitoring framework provide reasons to expect that imagination may inflate confidence that a childhood event occurred. However, people routinely produce myriad counterfactual imaginings (i.e., daydreams and fantasies) but usually do not confuse them with past experiences. To determine the effects of imagining a childhood event, we pretested subjects on how confident they were that a number of childhood events had happened, asked them to imagine some of those events, and then gathered new confidence measures. For each of the target items, imagination inflated confidence that the event had occurred in childhood. We discuss implications for situations in which imagination is used as an aid in searching for presumably lost memories.
\end{abstract}

People often imagine the past as being different from what it really was. Many investigators have argued that people spontaneously imagine alternatives to real events more in some settings than in others. These mental musings, called counterfactual thinking, have far-reaching implications. They influence, for example, judgments of regret, perceived happiness, and causality (Kahneman \& Tversky, 1982). For example, in one study subjects assigned more blame to an individual for a bad outcome when counterfactual thoughts - thoughts of what might have been done instead - would have undone the bad outcome (Wells \& Gavanski, 1989). The question we ask here is whether these counterfactual imaginings also affect a person's memory for the past. For example, suppose you imagined stumbling on something in your house, and before you realize what is happening you've shattered a window with your hand. Would you later be more likely to claim that this unfortunate event had happened to you?

We already know, from the social psychology literature, that imagining a future event increases the subjective likelihood that the event will occur (Carroll, 1978; Gregory, Cialdini, \& Carpenter, 1982; Sherman, Cialdini,

During much of this research, M.G. was supported by a postdoctoral training grant from the National Institutes of Alcohol Abuse \& Alcoholism. Thanks to Roddy Roediger, Steve Lindsay, Jonathan Schooler, Gary Wells, Kathleen McDermott, Chris Schacherer, Sue DuBreuil, and two anonymous reviewers for their helpful comments and suggestions. Correspondence should be addressed to M. Garry, Victoria University of Wellington, Department of Psychology, Wellington, New Zealand (e-mail: maryanne.garry@vuw.ac.nz) or to C. G. Manning (cmg@u.washington.edu) or E. F. Loftus, Department of Psychology, University of Washington, Seattle, WA 98195-1525.
Schwartzman, \& Reynolds, 1985). For example, consider Carroll's (1978) study on the power of imagination. Before the 1976 presidential election, subjects were asked to imagine either Carter or Ford winning the election. They were then asked to predict the outcome of the election using a scale from 0 (sure Carter will win) to 100 (sure Ford will win). Subjects who imagined that Carter had won were more certain that he eventually would; similarly, those who imagined Ford had won were more certain that he would later win.

But imagination does not always have these consequences. One determining variable is the ease with which the event can be imagined. Sherman et al. (1985) asked subjects to imagine getting a disease whose symptoms were either easy or difficult to imagine. The ease with which subjects stated they could imagine the symptoms was tied to likelihood estimates: Those who judged the symptoms as easy to imagine also tended to estimate the disease as more likely to occur; those who thought the symptoms were difficult to imagine thought it less likely to occur. Sherman et al. suggested that easily imagined future events somehow become more "available" in the sense pioneered by Tversky and Kahneman's (1973) research on judgment and decision making. Tversky and Kahneman proposed that when people are given uncertain conditions and asked to make outcome likelihood judgments, the more easily pictured outcomes are more "cognitively available," and seen as more likely. Put in different terms, the act of imagination may provide scaffolding, so that when subjects are tested, it is easier for them to build on this memorial framework. Perhaps if subjects imagined stumbling and shattering a window as a child, the 
event might also become more available, and subjects would become more confident that it had occurred.

Imagining a childhood event might also change memory for it by inducing source attribution errors (Johnson, 1988; Johnson, Hashtroudi, \& Lindsay, 1993). Simply put, source attribution errors occur when information is remembered, but its source is remembered incorrectly or not remembered at all. Koehler (1991) argued explicitly that source attribution errors were partly responsible for the increased confidence in the probability of imagined future events. He noted that the mere act of imagining a scenario forces people to create an alternate reality for a short time and to fit the imagined facts into their existing knowledge of the world. The imagination procedure generates event information that subjects may remember, even if they don't remember the source of the information. Event information becomes more available, and therefore more plausible; subjects become more confident that the event will occur.

A similar line of argument leads us to predict that subjects will also become more confident that imagined past events had occurred. The rationale for this prediction is straightforward. Imagination will produce event information, and the event information may become more accessible, but its source may be forgotten or misremembered. When subjects are later tested, the availability might make the past event seem more plausible, and they might become more confident that the past event had actually occurred.

There is even reason to believe that source confusion might be especially acute for the very distant events of childhood. For example, Johnson, Foley, Suengas, and Raye (1988) asked subjects to think of actual or imagined personal events from either the recent past or childhood and then to rate these memories on 39 different characteristics. There were far fewer significant differences (3/39) between actual and imagined childhood events than for actual and imagined recent events (20/39). Put another way, both experienced and imagined childhood memories contain far fewer qualitative differences that can be used to distinguish between what actually happened from what was only imagined. Perhaps the act of imagining a childhood event generates only diffuse information about it, but if even genuine childhood memories contain similar information, subjects might not have a reliable way of distinguishing between childhood fact and fantasy. In short, the act of imagining may generate information whose source later becomes confused, resulting in a stronger belief that the imagined childhood event actually occurred. Thus, source-monitoring research suggests why imagining a childhood accident window-shattering accident might promote greater confidence later that it actually occurred.

On the other hand, there are reasons to believe that imagining a childhood event will not increase confidence that it did occur. After all, people often imagine winning a multimillion dollar lottery jackpot, but they don't fool themselves into thinking that they have actually done so.
Most people daydream and imagine a variety of scenarios and outcomes yet don't routinely get confused between what really happened and what did not. Another reason to believe that imagination may have no effect on childhood memories is that subjects could make the conscious connection between imagining an event and being asked to make a judgment about it. Subjects who remember having imagined the event might become confident that their feeling of familiarity was attributable only to the recent act of imagining (Jacoby, Woloshyn, \& Kelley, 1989). In fact, these subjects might become more certain that the event never occurred than if they had been asked the very same question prior to the act of imagining.

So, a goal of the present research was to determine whether imagination leads to increased confidence that the event occurred. Suppose imagining a childhood event does promote this increased confidence (which we term imagination inflation); why should we care? One reason is the puzzle of how people can come to remember their past in ways that diverge sharply from reality. For instance, some people remember their past in more socially desirable ways (Abelson, Loftus, \& Greenwald, 1992), and people are often very confident about these memories. But the possibility of imagination inflation is not just theoretically interesting, for there are real-world instances in which imagination is deliberately used as a memory-recall tool. Law enforcement personnel sometimes repeatedly direct a suspect to imagine having participated in a criminal act as a means of obtaining a confession (Ofshe, 1992). In addition, some mental health professionals encourage a client to imagine an abusive childhood event as a way of recovering hidden memories. Maltz's (1991) specific technique is just one of many published examples: "Spend time imagining that you were sexually abused, without worrying about accuracy, proving anything, or having your ideas make sense. As you give rein to your imagination, let your intuitions guide your thoughts" (p. 50). If counterfactual imaginings can alter memory, we may have some evidence about a partial cause of these phenomena, another piece of the puzzle.

To explore whether imagination inflation occurs, we developed a three-stage procedure. First we asked subjects about a long list of possible childhood events, and they indicated whether or not these events had happened to them as children. Two weeks later, we asked them to imagine a few of these events. Finally, we gave the long list of possible childhood events to our subjects again, and they indicated whether or not the events had happened to them. To be specific, consider a group of subjects who all said that it was unlikely that they had ever broken a window with their hand. Later they imagine a scenario in which this happened to them, complete with how they tripped and fell, who else was there, and how they felt. Would these subjects later think it was more likely that they had broken a window with their hand as a child? Such a result would constitute empirical support for the hypothesis of imagination inflation. 


\section{METHOD}

\section{Subjects}

Forty-six subjects enrolled in introductory psychology courses at the University of Washington participated for course credit during the pretest. Of these, 38 completed all phases of the study.

\section{Materials}

A 40-item Life Events Inventory (LEI) was administered during the first session. It asked subjects to consider how certain they were that each event (or a very similar one) had or had not happened to them before the age of 10 (e.g., "Broke a window with your hand"; $1=$ definitely did not happen and $8=$ definitely did happen). They responded by circling the appropriate point on an 8-point scale. Three judges used pretest data to choose target items. Although the judges' selection criteria were informal, they were systematic in that they chose event items whose means indicated that they probably did not occur. The emergency room item did not fit the criteria, but it was selected as a target because it has been used in another study (Hyman, Husband, \& Billings, 1995). We report pretest descriptive statistics for these items in Table 1.

\section{Procedure}

Subjects participated in two sessions, in groups ranging from 1 to 10 each. In Session 1, they were told that the experimenters were interested in how vividly and completely people could imagine events, and that they would complete the LEI to gather baseline data on how frequently these events actually occurred. Subjects then completed the LEI at their own pace.

In Session 2, 2 weeks later, the eight items were split into two, fouritem subsets. Subsets were randomly assigned to subjects, who were then asked to imagine the four critical items in that subset, while the other subset served as a control. For instance, Subject 1 imagined the four events in Subset A, and did not imagine the four events in Subset $B$; Subject 2 imagined the four events in Subset $B$ but did not imagine the four events in Subset A. In both cases, items were imagined in specific steps.

Subjects were told that they would imagine some events that were described in packets that were on their desks. They were told that each page of the packet had a description of the events they were to imagine, as well as some questions about what they imagined. Subjects were instructed not to read ahead. Then the experimenter said,

You are going to imagine several events. Each time, you will read a brief description of an event. You will be given a few moments to picture the event, and then you will answer some questions about the image. You will be given more details to imagine, and then take a few moments to picture them. Then you will answer some questions about your image. Try to picture each event as clearly and completely as you can. It may help you to form a more complete mental picture if you include familiar places, people, and things in the imagined event. Also, close your eyes if that helps your imagination.

Subjects were asked if they had any questions about the instructions. When they were ready to begin, they turned over their packet and the experimenter began with the first event. First, the experimenter read a sentence or two to create the event setting: "Imagine that it's after school and you are playing in the house. You hear a strange noise outside, so you run to the window to see what made the noise. As you are running, your feet catch on something and you trip and fall." Subjects were given between 20 and $60 \mathrm{sec}$ to imagine the event that each experimenter read. If the experimenter observed that all subjects in a given session had completed their imagination task at the end of $20 \mathrm{sec}$, the experimenter moved to the next phase. If, however, some subjects were still engaged in the imagination task, the experimenter waited until a maximum of $60 \mathrm{sec}$ had passed. Subjects then wrote answers to short questions in their booklets. These questions were included to encourage compliance ("What did you trip on?"). The experimenter then read the action part of the event: "As you're falling you reach out to catch yourself and your hand goes through the window. As the window breaks you get cut and there's some blood." Subjects again completed short questions ("What are you likely to do next?"). This basic procedure was repeated for all four target items, and lasted about 2 min per item. Then the experimenter pretended to be slightly panicked, told the subjects that their original LEIs had been misplaced, and asked them to complete another copy. (No specific instruction was given as to whether subjects should fill it out as they had before.) In fact, this administration of the LEI was the posttest. Finally, subjects were debriefed.

\section{RESULTS}

The primary question in this study is whether imagining a childhood event inflates confidence that it occurred. Before addressing this question, we need to expand on our hypothesis by distinguishing between childhood events judged unlikely to have happened versus childhood events judged likely to have happened. Our interest was in events that were unlikely to have happened, because in this condition subjects must be using their imaginations to create an alternate reality. On the other hand, if subjects are asked to imagine an event that they previously said had happened to them, they might simply be recalling it - not imagining it. Recent research suggests that when subjects imagine something that actually did happen to them, the imagining task actually becomes a remembering task (Sarbin, 1995). Thus, we focused first and foremost on what happens when people imagine an event, not when they recall one.

We now turn our attention to events that were judged as unlikely to have happened, confining our analysis to the initial "did not happen" responses. These pretest responses constitute $76 \%$ of the total data; put another way, each subject reported that roughly $6 / 8$ critical items probably did not happen (responses of 1-4). Of course, the eight critical items differed in how likely they were to produce a 1-4 response. A high of $92 \%$ of subjects responded in the 1-4 range for "Got stuck in a tree and had to have someone help you down," while $45 \%$ produced a

Table 1

Pretest Answers for Critical Events

\begin{tabular}{lccccc}
\hline \multicolumn{1}{c}{ Event } & $M$ & $S D$ & Mdn & Range & Percentage $1-4^{*}$ \\
\hline Got in trouble for calling 911. & 1.97 & 2.27 & 1.0 & 7 & 87 \\
Had to go to the emergency room late at night. & 4.58 & 2.95 & 5.0 & 7 & 45 \\
Found a \$10 bill in a parking lot. & 2.47 & 2.20 & 1.0 & 7 & 79 \\
Won a stuffed animal at a carnival game. & 3.84 & 2.49 & 3.5 & 7 & 55 \\
Gave someone a haircut. & 2.66 & 2.22 & 1.0 & 7 & 76 \\
Had a lifeguard pull you out of the water. & 2.18 & 2.04 & 1.0 & 7 & 84 \\
Got stuck in a tree and had to have someone help you down. & 1.87 & 1.93 & 1.0 & 7 & 92 \\
Broke a window with your hand. & 2.13 & 2.03 & 1.0 & 7 & 89 \\
Overall & 2.71 & 2.44 & 1.0 & 7 & 76 \\
\hline
\end{tabular}

* $1-4$, responses on the eight-item scale indicating that a given event probably did not happen. 
1-4 response to "Had to go to the emergency room late at night." Across all items, the mean number of subjects who initially said an event did not happen was $29(74 \%)$, and the median was $31(80 \%)$.

To determine if imagination caused these subjects to become more confident that an event had occurred, we examined whether subjects moved up or down the scale. We calculated, for each critical item, the percentage of subjects whose responses increased, decreased, or did not change from the first to the second administration of the LEI test. We collapsed these change scores across all subjects and items, and display them separately according to whether or not the critical event was imagined. These data, for the 112 imagined items and 119 not-imagined items, are shown in Figure 1. Of particular interest are the positive change scores, which indicate that subjects move in the direction of becoming more confident that the event had happened to them.

As Figure 1 shows, the majority of scores did not change (57\% in the imagined condition and $65 \%$ in the notimagined condition). Additionally, when subjects did change their ratings, positive change scores were more likely to occur than were negative ones. But for the purposes of the present experiment, the most interesting result is found by comparing the bars on the extreme right of the figure: There was more positive change in the imagined items $(34 \%)$ than for the not-imagined items $(25 \%)$. In other words, subjects who initially reported that an event did not happen, but then imagined that it had, were more likely to increase their confidence that it had occurred when asked about it later than were subjects who did not imagine the event. However, because these data were obtained by combining all $1-4$ responses from all subjects, individual subjects contributed different numbers of events, so overall statistical comparisons cannot be made at this level. We offer these results only for illustrative purposes, and now direct our attention to each event item.

Would this intriguing pattern repeat for the event items individually? For each of the eight critical items we calculated the percentage of positive change. Figure 2 shows these data displayed according to whether or not the critical event was imagined. For each item, the right-hand bar reveals the percentage of subjects with increased confidence after imagining the event. A paired $t$ test treating items as cases showed that the mean difference was $8.2 \%$ greater for imagined items than for not-imagined items; this difference was significant $[t(7)=5.48, p=.0009, S E=$ 1.49, two-tailed, adjusted power at $\alpha=.05$ was .97]. The effect size, calculated as [mean difference/ $S D_{\text {not imagined }}$, was a medium-to-large 0.72 . So, for example, in the "Broke window" event, $24 \%$ of subjects who imagined the event increased their subjective confidence that it had happened to them, while the corresponding figure for subjects who had not imagined it was only $12 \%$.

Why does imagining an event lead to more positive changes than not imagining the event? One possible explanation is that the act of imagination simply makes the event seem more familiar at the time the posttest LEI is completed. Another possibility, however, is that the act of imagination reminds some subjects of a true experience from their past. If this "reminder" hypothesis is correct, we might expect to see at least some instances in which subjects initially give a low score indicating that the event probably hadn't happened to them, but the second time jump to a score of 8 , indicating that the event definitely did happen to them. On the other hand, if some subjects do make a "big jump" (i.e., they move from an initial score of 1-4 to a final score of 8 ), it may not be because they remember a genuine experience at all: It may be that imagining the event makes it seem very real, and subjects become quite sure that it happened.

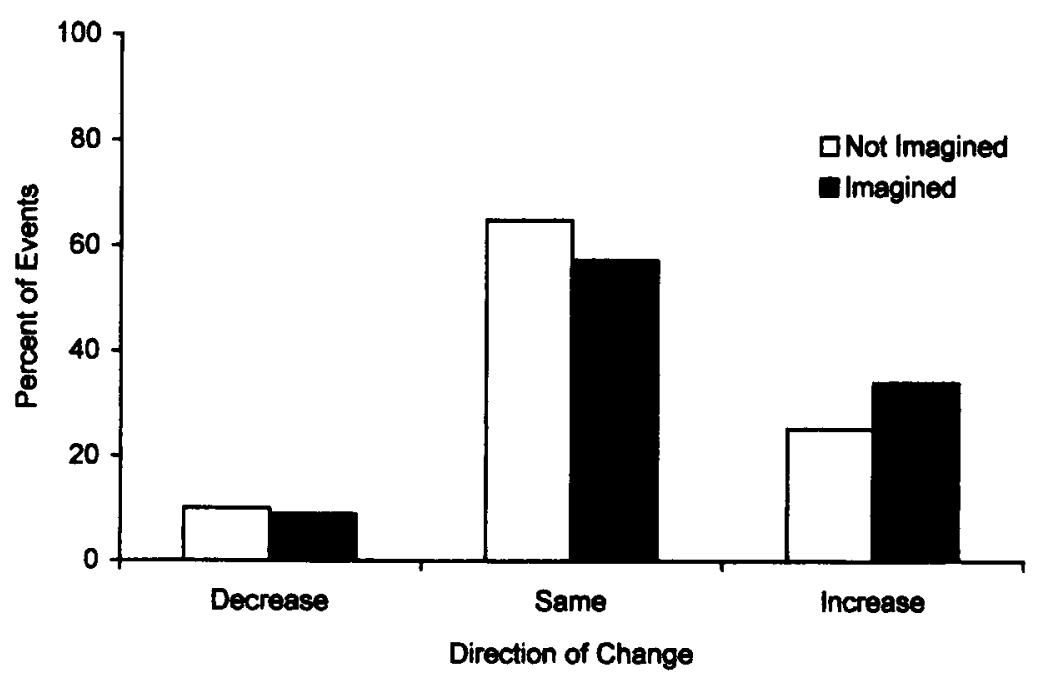

Figure 1. Percentage of events staying the same, increasing, and decreasing for subjects who initially responded $1-4$ (responses indicating that the critical items probably did not happen). 

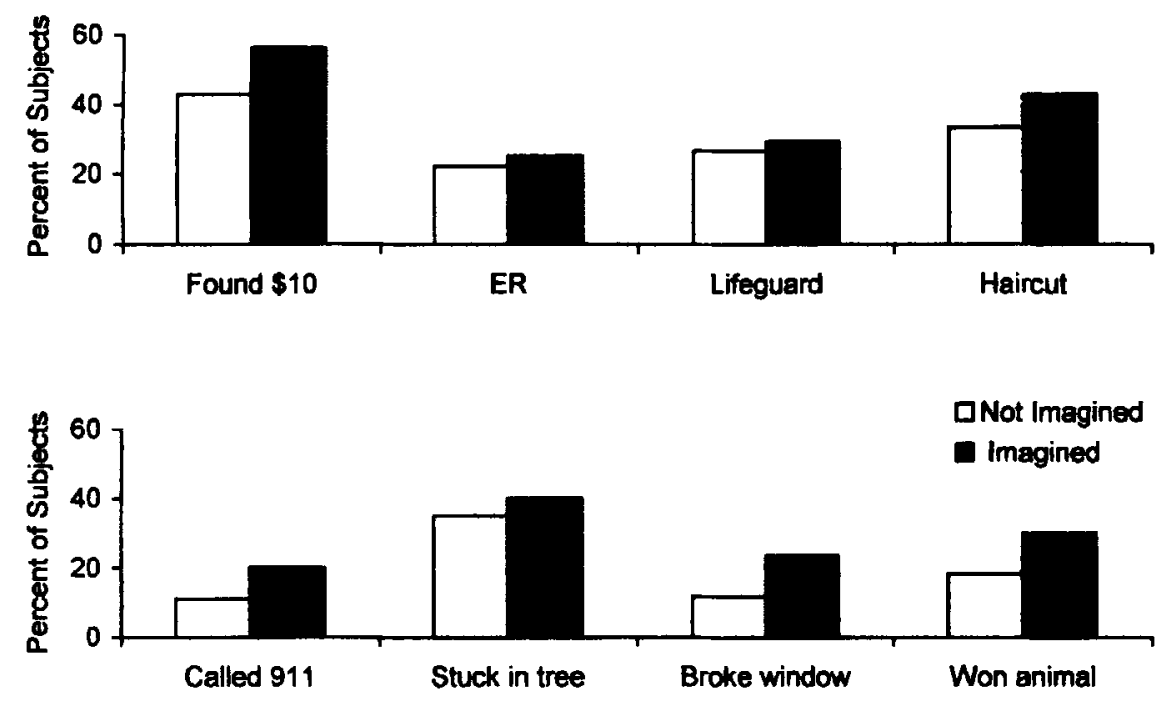

Figure 2. Percentage of subjects who increased on each item (for subjects who initially responded 1-4; that is, responses indicating that the critical items probably did not happen).

These are highly speculative inferences, and they rest on the assumption that being reminded of a genuine event causes one to be certain. However, to explore the possibilities, we calculated the number of "big jumps," defined as an increase to a score of 8 on the posttest. Such jumps were relatively rare, occurring in only 6 of the 112 imagined items, and in 2 of the 119 not-imagined items. These "big jumpers" were found in the following items from Table 1 (cases are in parentheses): "Found $\$ 10$ " (2 imagined); "Lifeguard" ( 2 imagined); "Emergency room" (1 not imagined); "Stuffed animal" (1 imagined); and "Haircut" ( 1 imagined, 1 not imagined). When these cases were removed from the analysis and change scores were collapsed across subjects and items, there was still an overall tendency toward imagination inflation. That is, there were still more positive change scores for imagined than not-imagined subjects $(29.9 \%$ vs. $23.4 \%)$, and all but the "Lifeguard" item still showed an imagination effect. Over the eight items, the mean difference was $6.55 \%$ greater change in imagined items than not-imagined items. A paired $t$ test treating items as cases showed that this mean difference was significant $[t(7)=3.02, p=$ $.01, S E=2.17$, two-tailed; adjusted power at $\alpha=.05$ was .53]. Effect size was a medium .55.

What kinds of change scores were produced by the subjects who originally did not think an event happened to them, and did not imagine it? Let us return to Figure 2 and examine what happened to these subjects. The lefthand bar for each item shows the percentage of subjects with positive change scores after merely being asked about the event twice, on the pretest and posttest. A paired $t$ test treating items as cases showed that when subjects did change their responses between the first and second LEI tests, the percentage of subjects with positive change scores was significantly greater than the percentage with negative change scores [mean difference $=13.9 \%, t(7)=$ $2.67, p=.032, S E=5.20$, two-tailed; adjusted power at $\alpha=.05$ was .41 ]. For instance, $43 \%$ of subjects who took only the pretest and posttest became more confident that they had found a $\$ 10$ bill, and $7 \%$ of them became less confident. Thus, even when subjects who did not imagine an event changed their answers, they tended to report greater rather than less confidence that it had occurred. Did these subjects develop false memories because event items were repeated? Of course, there are other explanations for this result. Briefly, it could be regression to the mean. It could be that the second test promotes more accurate recall, or it could be that the second test causes the item to become more plausible, and that increased confidence does not point to completely developed false memories so much as to increased plausibility that they might have occurred. These issues are discussed in more depth later.

We have shown that when subjects imagine an event they do not think happened, they tend to become more confident that it did happen. But what about subjects who initially think an event probably did happen? Would imagination make them even more confident that an event had occurred? Although not the main question in our research, it is worth addressing. To examine the effect of imagination on events thought likely to have happened, we collapsed change scores for them across all subjects and items. We included only items initially judged as 5-7, removing the data for items initially reported as an 8 because these ratings could not increase. The most common outcome among these "probably did happen" subjects in the imagined condition was to stay the same, and the most common change in the not-imagined condition was to become less confident. Additionally, positive change occurred more often for not-imagined items than 
for imagined items $(36 \%$, or $8 / 22$, vs. $19 \%$, or $4 / 21)$. However, because there were so few items, statistical analysis is inappropriate, and we avoid further interpretation.

\section{DISCUSSION}

The major result from this experiment is that imagining a selfreported counterfactual event increased confidence that the event did happen. This result complements earlier findings on the power of imagination to increase people's subjective sense of the probability that a future event will occur (see, e.g., Sherman et al., 1985). Why should imagination influence reports of both future and past events in a similar way? On the face of it, future events and past events do not seem to have much in common. After all, future events are obviously not subject to memory reconstruction (as judged against objective, historical truth), but past events are. For instance, witnessed events are often reported inaccurately (Belli, 1989); more to the point, personal experiences are also subject to various memory distortions (Loftus, 1993). But Johnson and Sherman (1990) argued for less simplistic categories than mere past, present, and future. In their view, both past and future are constructions of the present. The present constantly flows into the past, so the past is always changing, and the future is always being constrained by this changing past. J. J. Gibson (1977/1986) made a similar point when he challenged psychologists to find the place where the present stops and the past takes over. That confidence-promoting effects are found for both future and past events suggests that the timeline is not necessarily so neatly carved up into past, present, and future.

Imagination did not have a systematic effect on events that were initially judged to have happened. Of course, the mental activity involved in imagining an actual past event is probably very different from the mental activity involved when one imagines something that did not happen. In other words, an instruction to imagine an event that did not happen may lead people to create an alternate reality, but an instruction to imagine an event that did happen may lead them simply to recall the past event. Thus the mental processes involved when people imagine the real versus the unreal past may be quite different.

In addition to the finding that the act of imagination promotes greater likelihood estimates, there was also a slight tendency for the repeating of an item to produce higher scores. For example, being asked if you had ever broken a window with your hand, then being asked again 2 weeks later, may lead to a small increase in likelihood scores - even without any intervening imagination. Of course, this increase might be nothing more than regression to the mean, but in other domains an analogous "repetition" effect has been found. For example, Arkes and colleagues (Arkes, Boehm, \& Xu, 1991; Arkes, Hackett, \& Boehm, 1989) have shown that validity ratings of true and false statements of fact that have been repeated are greater than validity ratings of unrepeated statements. Even with repeated tests, the largest gains in validity occur between the first and second tests.

Why should there be any gain at all in validity? Subjects do not have access to new, supporting information; they simply read the propositions again. One explanation that Arkes and his colleagues have offered for the repetition effect is that subjects tend to rely on familiarity as one measure of validity, even when the facts are constant. In other words, truth is inferred on the basis of what might be an easier cognitive route: It may be easier to judge the familiarity of content than it is to judge the content itself. In the context of imagination inflation, then, when sub jects read an event in the second LEI, they may take the familiarity of the item to mean that it happened. Of course, such a mechanism is a classic case of source confusion, and it is worth repeating (if only to increase the validity of our argument) that source confusion is one of the explanations for the effects seen in the imagine-the-future literature (Koehler, 1991). This entire line of reasoning is similar to that in arguments made about the venerable "sleeper effect" (Pratkanis, Greenwald, Leippe, \& Baumgardner, 1988), in which content and source eventually become dissociated, and a proposition that would immediately have been judged invalid (because its source was suspect) is now judged as true.

In short, if the work of Arkes et al. $(1989,1991)$ shows that asking twice about a purported fact results in higher validity ratings, it seems plausible that asking twice about a purported event may result in higher likelihood estimates. Perhaps pondering whether or not an event oc- curred involves a subset of the same strategies that are involved in imagination. On the other hand, we should exercise caution in going too far afield with a discussion of repetition effects; the effects observed in the present experiment might actually be explained by regression to the mean, and research is needed to specifically investigate the possibility of a repetition effect for past events.

Of course, there are other explanations for the present results. One account for at least some of these data is what we will call the reinterpretation hypothesis. It supposes that a given item is interpreted more broadly on the LEI posttest than it is on the pretest. In other words, the item expands to accommodate the event. The reinterpretation mechanism is entirely plausible, and it is not clear that it would generally work to produce imagination inflation. Reinterpretation could easily lead to imagination deflation. To see why, consider that the imagination procedure leads subjects to imagine a specific, complex scenario in which they are the protagonists. Thus, the "imagined" subjects should have more constrained item interpretations, and the "not-imagined" subjects should have a greater tendency to reinterpret items more broadly, permitting more instances of events that fit the item; such a pattern would work against the imagination inflation effect. In short, a reinterpretation mechanism might inflate confidence in some item and event combinations, and deflate confidence in others.

Another explanation for the increased confidence we observed after imagination involves the concept of hypermnesia. Hypermnesia is the tendency toward increased recall over successive tests. In a typical hypermnesia experiment, subjects study word lists and then take several successive tests. Recall performance often improves steadily over repeated testing (e.g., Roediger \& Payne, 1985). Under the hypermnesia explanation, the design of the present experiment merely promotes the increasingly accurate recall of genuinely experienced events. For instance, the first LEI test is the first occasion to think about an event, and it thus produces the least accurate memory. The second test produces more accurate memory than the first, and the act of imagination is yet another chance to think about the target event. Subjects who imagine an event are given an additional opportunity to think about it, which explains imagination inflation. The newly remembered event could conceivably be one that fits the LEI item well, or one that fits somewhat.

We cannot rule out the hypermnesia possibility given the data we collected here. Perhaps imagination inflation is sometimes due to new genuine memories, and sometime to enhanced confidence about false memories. This is a question worthy of further research with more probative methods. Before leaving the topic of hypermnesia, however, we note two points about how the present study differs considerably from the typical hypermnesia study. The first difference is on what is being measured. The relatively neat content of hypermnesiac memories (see, e.g., Roediger \& Payne, 1985) may not generalize to the messy complexity of real-life memories (see, e.g., Neisser, 1986). The second difference is in how these memories are measured. Hypermnesia is found with recall tests, but not with recognition tests (Payne \& Roediger, 1987). However, we used a test that cannot be categorized neatly as either recall or recognition. Subjects were asked to indicate which of 40 possible childhood experiences had occurred. The items did not describe very simple experiences. Instead, they described events of some complexity, in that multiple idea units were in all of the critical items (except for the "Haircut event"; see Table 1). For example, subjects were not asked if they had ever found any amount of money anywhere at any time in their lives; they were asked if they had ever found a $\$ 10$ bill in a parking lot before they were 10 years old.

In the present research, we do not know if imagining the event itself might cause imagination inflation, or if one must be the agent in the event. Source confusions might be increased (and imagination inflation be most pronounced) when subjects imagine themselves, say, finding a $\$ 10$ bill in a parking lot, but not if they imagine Bill Clinton finding the same $\$ 10$ bill. Imagining oneself should create more kinds of weak information (e.g., weak kinesthetic and haptic information) that could later increase familiarity. We also do not know which subjects in which events-if any-recognized that an LEI item asked about an event that had been imagined several minutes earlier. Future research is needed to ascertain whether subjects are drawing this link, and not showing imagination inflation when they do. Even if subjects do make a conscious link between the LEI item and the imagination exercise, we might still see an imagination effect. For instance, these subjects might not think 
that all of the familiarity associated with the asked-about event was due to the earlier act of imagination, or they might think that the event is familiar for reasons in addition to imagining it. More to the point, if some subjects were indeed meeting the demand of the experiment by deliberately inflating their scores, we should have seen increased confidence among those subjects who originally were confident that a given event had happened. Instead, we saw no particular pattern in that category.

These results suggest appropriate restraint in situations in which imagination is used as an aid in searching for or shoring up presumably lost memories. When the police repeatedly ask a suspect to imagine his possible role in a murder he does not remember, or when a mental health professional repeatedly encourages a client to imagine an abusive childhood event, these imagination activities may unknowingly promote a greater belief that particular episodes occurred. The search for fact may create a fiction. Such is the power of imagination, long ago recognized by Keats (1817, cited in Bartlett, 1992, p. 417), who said, "The Imagination may be compared to Adam's dream--he awoke and found it truth."

\section{REFERENCES}

Abelson, R. P., Loftus, E. F., \& Greenwald, A. G. (1992). Attempts to improve the accuracy of self-reports of voting. In J. M. Tanur (Ed.), Questions about survey questions: Meaning, memory, expression, and social interactions in surveys (pp. 138-153). New York: Russell Sage.

ARKes, H. R., BoehM, L. E., \& XU, G. (1991). Determinants of judged validity. Journal of Experimental Social Psychology, 27, 576-605.

ARKes, H. R., HacketT, C., \& Boenm, L. (1989). The generality of the relation between familiarity and judged validity. Journal of Behavioral Decision Making, 2, 81-94.

Bartlett, J. (1992). Familiar quotations: A collection of passages, phrases, and proverbs traced to their sources in ancient and modern literature (16th ed.). Boston: Little, Brown.

BELLI, R. F. (1989). Influences of misleading postevent information: Misinformation interference and acceptance. Journal of Experimental Psychology: General, 118, 72-85.

CARROLL, J.S. (1978). The effect of imagining an event on expecations for the event: An interpretation in terms of the availability heuristic. Journal of Personality \& Social Psychology, 36, 1501-1511.

Gisson, J. J. (1977/1986). The ecological approach to perception. Hillsdale, NJ: Erlbaum.

Gregory, W. L., Cialdini, R. B., \& Carpenter, K. M. (1982). Selfrelevant scenarios as mediators of likelihood estimates and compliance: Does imagining make it so? Journal of Personality \& Social Psychology, 43, 88-99.

Hyman, I. E., Husband, T. H., \& Billings, F. J. (1995). False memories of childhood experiences. Applied Cognitive Psychology, 9, 181-197.

JACOBY, L. L., WolOSHYN, V., \& KelleY, C. (1989). Becoming famous without being recognized: Unconscious influences of memory produced by dividing attention. Journal of Experimental Psychology: General, 118, 115-125.

JoHnson, M. K. (1988). Reality monitoring: An experimental phenomenological approach. Journal of Experimental Psychology: General, 117, 390-394.
Johnson, M. K., Foley, M., Suengas, A. G., \& Raye, C. L. (1988) Phenomenal characteristics of memories for perceived and imagined autobiographical events. Journal of Experimental Psychology: General, 117, 371-376.

Johnson, M. K., Hashtroudi, S., \& Lindsay, D. S. (1993). Source monitoring. Psychological Bulletin, 114, 3-28.

Johnson, M. K., \& Sherman, S. J. (1990). Constructing and reconstructing the past and the future in the present. In E. T. Higgins \& R. M. Sorrentino (Eds.), Handbook of motivation and social cognition: Foundations of social behavior (pp. 482-526). New York: Guilford Press.

Kahneman, D., \& Tversky, A. (1982). The simulation heuristic. In D. Kahneman, P. Slovik, \& A. Tversky (Eds.), Judgement under uncertainty: Heuristics and biases (pp. 201-208). New York: Cambridge University Press.

KOEHLER, D. J. (1991). Explanation, imagination, and confidence in judgement. Psychological Bulletin, 110, 499-519.

LoFTUS, E. F. (1993). The reality of repressed memories. American Psychologist, 48, 518-537.

MaLTz, W. (1991). The sexual abuse healing journey. New York: Harper/Collins.

NEISSER, U. (1986). Nested structure in autobiographical memory. In D. C. Rubin (Ed.), Autobiographical memory (pp. 71-81). New York: Cambridge University Press.

OFSHE, R. J. (1992). Inadvertent hypnosis during interrogation: False confession due to dissociative state: Mis-identified multiple personality and the satanic cult hypothesis. International Journal of Clinical \& Experimental Hypnosis, 40, 125-156.

PAYNE, D. G., \& RoEDIGER, H. L., III (1987). Hypermnesia occurs in recall but not in recognition. American Journal of Psychology, 100, 145-165.

Pratkanis, A. R., Greenwald, A. G., LeipPe, M. R., \& BaumgardNER, M. H. (1988). In search of reliable persuasion effects: III. The sleeper effect is dead: Long live the sleeper effect. Journal of Personality \& Social Psychology, 54, 203-218.

Roediger, H. L., III, \& PAYNE, D. G. (1985). Recall criterion does not affect recall level or hypermnesia: A puzzle for generate/recognize theories. Memory \& Cognition, 13, 1-7.

SARBIN, T. R. (1995). On the belief that one body may be host to two or 'more personalities. International Journal of Clinical \& Experimental Hypnosis, 43, 163-183.

Sherman, S. J., Cialdini, R. B., Schwartzman, D. F., \& Reynolds, K. D. (1985). Imagining can heighten or lower the perceived likelihood of contracting a disease: The mediating effect of ease of imagery. Personality \& Social Psychology Bulletin, 11, 118-127.

TversKY, A., \& KahNeman, D. (1973). Availability: A heuristic for judging frequency and probability. Cognitive Psychology, 5, 207-232.

WELLS, G. L., \& GaVANSKI, I. (1989). Mental simulation of causality. Journal of Personality \& Social Psychology, 56, 161-169.

(Manuscript received April 7, 1995; revision accepted for publication November 8,1995 .) 